Article

\title{
SERS-Based Flavonoid Detection Using Ethylenediamine- $\beta$-Cyclodextrin as a Capturing Ligand
}

\author{
Jae Min Choi ${ }^{1}$, Eunil Hahm ${ }^{2}$, Kyeonghui Park ${ }^{3}$, Daham Jeong ${ }^{3}$, Won-Yeop Rho ${ }^{2}$, Jaehi Kim ${ }^{4}$, \\ Dae Hong Jeong ${ }^{4}$, Yoon-Sik Lee ${ }^{5}$, Sung Ho Jhang ${ }^{6}$, Hyun Jong Chung ${ }^{6}$, Eunae Cho ${ }^{1}$, \\ Jae-Hyuk Yu ${ }^{7}$, Bong-Hyun Jun ${ }^{2, *}$ and Seunho Jung ${ }^{1,3, *}$ \\ 1 Center for Biotechnology Research in UBITA (CBRU), Institute for Ubiquitous Information Technology and \\ Application (UBITA), Konkuk University, Seoul 05029, Korea; jm.choi.25@gmail.com (J.M.C.); \\ echo@konkuk.ac.kr (E.C.) \\ 2 Department of Bioscience and Biotechnology, Konkuk University, Seoul 05029, Korea; \\ dkhei0525@hanmail.net (E.H.); Rho72@snu.ac.kr (W.-Y.R.) \\ 3 Department of Bioscience and Biotechnology, Microbial Carbohydrate Resource Bank (MCRB) \& Center for \\ Biotechnology Research in UBITA (CBRU), Konkuk University, Seoul 05029, Korea; \\ kyeonghee17@naver.com (K.P.); darkamir@nate.com (D.J.) \\ 4 Department of Chemistry Education, Seoul National University, Seoul 08826, Korea; susia45@snu.ac.kr (J.K.); \\ jeongdh@snu.ac.kr (D.H.J.) \\ 5 School of Chemical and Biological Engineering, Seoul National University, Seoul 08826, Korea; \\ yslee@snu.ac.kr \\ 6 Department of Physics, Konkuk University, Seoul 05029, Korea; shjhang@konkuk.ac.kr (S.H.J.); \\ hjchung@konkuk.ac.kr (H.J.C.) \\ 7 Departments of Bacteriology and Genetics, University of Wisconsin-Madison, Madison, WI 53706, USA; \\ jyu1@wisc.edu \\ * Correspondence: bjun@konkuk.ac.kr (B.-H.J.); shjung@konkuk.ac.kr (S.J.); Tel.: +82-450-3520 (S.J.) \\ Academic Editor: Helmut Cölfen \\ Received: 10 September 2016; Accepted: 30 December 2016; Published: 6 January 2017
}

\begin{abstract}
Ethylenediamine-modified $\beta$-cyclodextrin (Et- $\beta$-CD) was immobilized on aggregated silver nanoparticle (NP)-embedded silica NPs $\left(\mathrm{SiO}_{2} @ \mathrm{Ag} @ \mathrm{Et}-\beta-\mathrm{CD} \mathrm{NPs}\right)$ for the effective detection of flavonoids. Silica NPs were used as the template for embedding silver NPs to create hot spots and enhance surface-enhanced Raman scattering (SERS) signals. Et- $\beta$-CD was immobilized on Ag NPs to capture flavonoids via host-guest inclusion complex formation, as indicated by enhanced ultraviolet absorption spectra. The resulting $\mathrm{SiO}_{2} @ \mathrm{Ag} @ E t-\beta-C D$ NPs were used as the SERS substrate for detecting flavonoids, such as hesperetin, naringenin, quercetin, and luteolin. In particular, luteolin was detected more strongly in the linear range $10^{-7}$ to $10^{-3} \mathrm{M}$ than various organic molecules, namely ethylene glycol, $\beta$-estradiol, isopropyl alcohol, naphthalene, and toluene. In addition, the SERS signal for luteolin captured by the $\mathrm{SiO}_{2} @ \mathrm{Ag} @ \mathrm{Et}-\beta-\mathrm{CD}$ NPs remained even after repeated washing. These results indicated that the $\mathrm{SiO}_{2} @ \mathrm{Ag} @ \mathrm{Et}-\beta-\mathrm{CD}$ NPs can be used as a rapid, sensitive, and selective sensor for flavonoids.
\end{abstract}

Keywords: cyclodextrin; ethylenediamine cyclodextrin; surface-enhanced Raman scattering (SERS); flavonoids

\section{Introduction}

Flavonoids are secondary metabolites found in several fruits, grains, flowers, vegetables, teas, and wines [1]. They are important pigments in flowers, and are responsible for ultraviolet (UV) filtration and symbiotic nitrogen fixation [2]. Furthermore, they serve as cell cycle inhibitors or chemical 
messengers, and have interesting beneficial effects on human health in various applications [3-8]. Typically, naturally occurring flavonoids are classified as flavonols, flavonones, flavones, flavanonols, flavans, isoflavonoids, or anthocyanidins. In particular, luteolin ( $3^{\prime}, 4^{\prime}, 5,7$-tetrahydroxyflavone) has been reported to exhibit antimicrobial, anti-inflammatory, and anticancer activities [9-11]. Despite these interesting properties, analytical methods for the detection of flavonoids have been limited to chromatography [12,13], capillary electrophoresis [14], and flow injection analysis [15], which are laborious and time-consuming. Moreover, UV detectors show relatively low sensitivity, and capillary electrophoresis is not selective for flavonoids [14].

Surface-enhanced Raman scattering (SERS) is a sensitive analytical technique for in situ detection [16,17] of various molecules such as flavonoids. A majority of studies have focused on the detection of target molecules located near a metal nanoparticle (NP) surface; these molecules are analyzed using their target SERS peaks. However, this direct detection method has several disadvantages, owing to the lack of specificity and different affinities of analytes for the metal surface. Hence, ligands and small organic molecules with high affinities for the target are introduced onto the metal surface in order to detect the target specifically. Although this approach can be used to overcome the limitations associated with the direct detection method, only a few ligands have been reported thus far.

Cyclodextrins (CDs) are cyclic oligosaccharides composed of six, seven, or eight D-glucopyranose units attached through $\alpha-1,4$ linkages [18]. CDs have a rigid, torus-shaped hydrophobic cavity, which can form inclusion complexes with a wide range of guest molecules $[19,20]$; this property has been exploited for the detection of flavonoids [21-23]. Although various applications of CDs have been reported [24-27], native CDs still have limitations [28]. To overcome their limited recognition ability, various CD modification methods have been reported [29].

Despite the importance of flavonoids, their selective detection using CD-immobilized nanoparticles has not been reported yet. There are several studies on the identification of flavonoid structures, the identification of the two labile chemical groups of flavonoids [30-33], and the prediction of the properties of flavones using SERS [33-35]. The structural change of quercetin in the presence of metal ions has also been investigated using SERS [36]. SERS has also been used to identify flavonoids that originate from plants and to determine the main efficacious ingredients in the extract of wild Rubus parvifolius Linn (RPL) [37]. Given their importance, it is imperative to utilize selective analytical techniques to detect and identify flavonoid molecules in a mixture.

Recently, our group reported the use of $\beta$-CD-dimer-assembled SERS substrates, which generate significantly enhanced Raman signals, for the detection of polycyclic aromatic hydrocarbons (PAHs) [38]. In this study, ethylenediamine-modified $\beta-C D$ (Et- $\beta-C D)$, which exhibits high affinity for flavonoids, was immobilized on Ag-NP-embedded silica NPs $\left(\mathrm{SiO}_{2} @ \mathrm{Ag} @ \mathrm{Et}-\beta-\mathrm{CD}\right.$ NPs), which were used as a powerful SERS substrate for the detection of flavonoids, namely hesperetin (Hes), naringenin (Nar), quercetin (Que), and luteolin (Lut). In addition, $\mathrm{SiO}_{2} @ \mathrm{Ag} @ \mathrm{Et}-\beta-\mathrm{CD}$ NPs detected flavonoids selectively, providing a tool for quantitative Lut detection.

\section{Results and Discussion}

\subsection{Preparation of Et- $\beta$-CD-Immobilized Ag-NP-Embedded Silica NPs (SiO $@ A g @ E t-\beta-C D N P s)$}

$\mathrm{SiO}_{2} @ \mathrm{Ag} @ \mathrm{Et}-\beta-\mathrm{CD}$ is composed of Et- $\beta-\mathrm{CD}$ and Ag-NP-assembled nanomaterials. To determine the colloidal stability of $\mathrm{SiO}_{2} @ \mathrm{Ag}$, the zeta potential was measured using a zeta potential analyzer. The zeta potential value of pristine $\mathrm{SiO}_{2} @ \mathrm{Ag}$ was $-30.88 \mathrm{mV}$. After conjugation with Et- $\beta-\mathrm{CD}$, the zeta potential was $41.58 \mathrm{mV}$. These high zeta potential values of both the $\mathrm{SiO}_{2} @ \mathrm{Ag}$ and $\mathrm{SiO}_{2} @ \mathrm{Ag} @ \mathrm{Et}-\beta-\mathrm{CD}$ NPs indicated good colloidal stability. In general, particles in suspension have either a large negative or positive zeta potential value; as a result, there would be no chance of aggregation [39]. Et- $\beta-C D$ comprises amine groups, which exhibit affinity for silver and serve as ligands for capturing flavonoids via host-guest inclusion complexation (Figure S1). As an SERS substrate, the Ag-NP-embedded silica NPs (Ag NPs@SiO ${ }_{2}$ ) can enhance SERS signals via their assembled nanostructure $[38,40]$. For the preparation of the Et- $\beta$-CD-immobilized Ag-NP-assembled nanomaterials, Et- $\beta$-CD and Ag-NP-assembled nanomaterials were synthesized according to a previously reported procedure [38]. 


\subsubsection{Characterization of Et $-\beta-C D$}

Et- $\beta$-CD was synthesized through monotosylation followed by reaction with ethylenediamine, as described in the experimental section (Figure S1). The structure of synthesized Et- $\beta$-CD was confirmed by ${ }^{1} \mathrm{H}$ and ${ }^{13} \mathrm{C}$ nuclear magnetic resonance (NMR) spectroscopy. In the ${ }^{1} \mathrm{H}$ NMR spectrum, the signals observed at 5.05, 3.64, 3.84, 3.57, 3.95, and $3.86 \mathrm{ppm}$ (Figure S2a) corresponded to protons H1 to $\mathrm{H} 6$ of the glucopyranose unit, respectively. The peaks of protons $\mathrm{H} 7$ and $\mathrm{H} 8$ in the ethylenediamine moiety were observed at 2.76 and $2.73 \mathrm{ppm}$, respectively. In the ${ }^{13} \mathrm{C}$ NMR spectra, signals observed at 101.8, 72.1, 73.1, 81.2, 70.5, and 60.3 ppm corresponded to carbons C1-C6, respectively (Figure S2b). In addition, the peaks of carbons $\mathrm{C} 7$ and $\mathrm{C} 8$, in the ethylenediamine moiety, were observed at 39.4 and $49.0 \mathrm{ppm}$, respectively. Furthermore, the peak for the substituted $\mathrm{C}^{\prime}$ carbons was slightly shifted (49.2 ppm), and distinct from the signal of the unsubstituted C6 carbon (60.3 ppm). NMR spectroscopy data indicated that the ethylenediamine moiety was attached to the $\mathrm{C} 6$ atom of native $\beta-C D$ and that Et- $\beta-C D$ was synthesized successfully.

\subsubsection{UV Absorption Spectra of the Inclusion Complex of Et- $\beta-C D$ with Flavonoids}

Figure 1 shows the chemical structures of the four flavonoids. Figure 2 shows their UV absorption spectra in the absence and presence of $2 \mathrm{mM} \beta-\mathrm{CD}$, 2-hydroxypropyl- $\beta-\mathrm{CD}$ (HP- $\beta-\mathrm{CD}$ ), and Et- $\beta-C D$. Figure $2 a, b$ shows the UV absorption spectra of Hes and Nar with various $\beta-C D$ derivatives. The $\lambda_{\max }$ of Hes (or Nar) and its corresponding complexes with $\beta-C D, H P-\beta-C D$, and Et- $\beta-C D$ was at $322 \mathrm{~nm}$, and the $\lambda_{\max }$ of the Hes (or Nar) complex with dimethyl- $\beta-C D$ (DM- $\beta-C D$ ) was at $288 \mathrm{~nm}$. These blue-shifts in the spectra were attributed to hydrogen bonds between the host $D M-\beta-C D$ and Hes (or Nar), possibly because hydrogen bonding can lower the energy of the " $n$ " (non-bonding) orbitals [41]. Hydrogen bonding is considered one of the main forces driving the formation of an inclusion complex. UV absorption was primarily enhanced upon complexation of Et- $\beta$-CD with Hes (or Nar). Figure $2 \mathrm{c}$, d shows the UV absorption spectra of the Que and Lut complexes, respectively; their UV absorptions also increased because of complexation. Enhancement of UV absorption followed the order of Et- $\beta-C D>H P-\beta-C D>D M-\beta-C D>\beta-C D$. Enhanced UV absorption was observed for Et- $\beta-C D$ with all four flavonoids. The enhancement was caused by the outstanding complex-forming ability of Et- $\beta$-CD compared to those of the other $\beta$-CD derivatives. During complexation, guest molecules were transferred from an aqueous medium to the hydrophobic environment, resulting in UV absorption changes [42-46]. In addition, significant differences in UV absorption were not observed for the different flavonoids (Figure S3). The maximum absorbance peaks for $\mathrm{SiO}_{2} @ \mathrm{Ag} @ \mathrm{Et}-\beta-\mathrm{CD}$, after reacting with Lut or Que, increased in intensity, owing to the combination effect on the extinction coefficient of the nanomaterials due to visible light. In contrast, marginal changes in absorbance intensity were observed with other flavonoids, namely Nar and Hes.
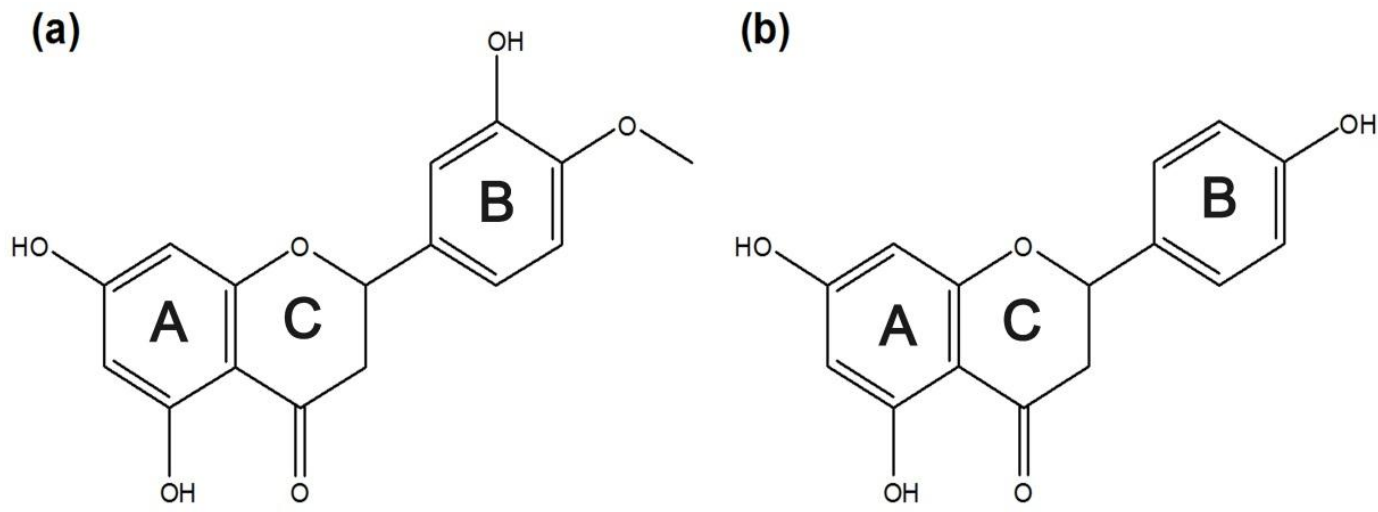

Figure 1. Cont. 
(c)<smiles>O=c1c(O)c(-c2ccc(O)c(O)c2)oc2cc(O)cc(O)c12</smiles><smiles></smiles>

Figure 1. Chemical structures of the flavonoids: (a) hesperetin; (b) naringenin; (c) quercetin; and (d) luteolin.

(a)

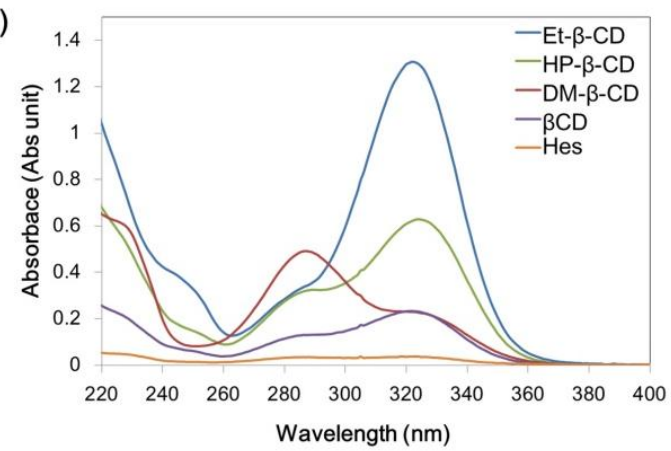

(c)

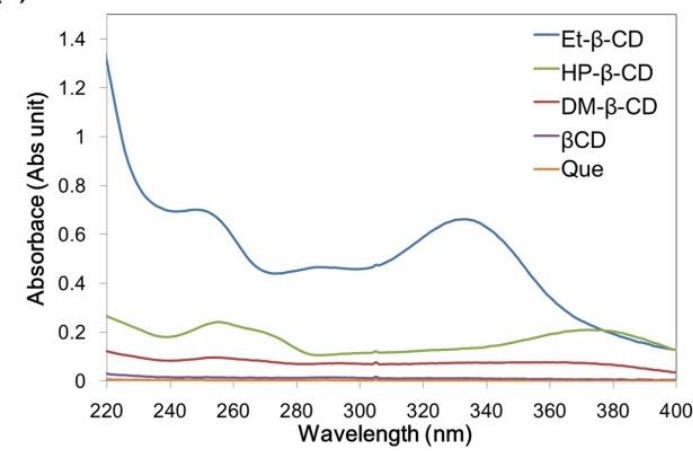

(b)

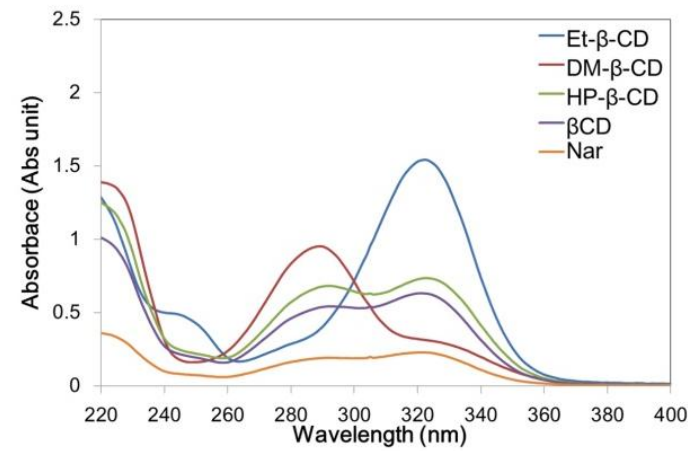

(d)

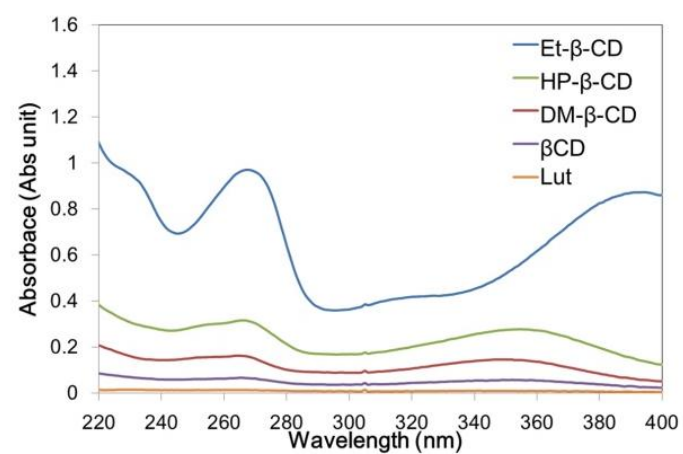

Figure 2. Ultraviolet-visible (UV-Vis) absorption spectra of the flavonoids and their complexes: (a) Hesperetin (Hes); (b) Naringenin (Nar); (c) Quercetin (Que); and (d) Luteolin (Lut) in the absence (orange) and presence of $\beta$-cyclodextrin ( $\beta-C D$, purple), dimethyl- $\beta-C D$ (DM- $\beta-C D$, red), 2-hydroxypropyl- $\beta$-CD (HP- $\beta-\mathrm{CD}$, green), and ethylenediamine-modified $\beta-\mathrm{CD}$ (Et- $\beta$-CD, blue).

\subsubsection{Preparation of $\mathrm{SiO}_{2} @ A g @ E t-\beta-C D$}

Ag-NP-assembled silica NPs were prepared according to a previously reported method [38,40]. Silica NPs, as the core, were synthesized using the Stöber method [47], and their size was controlled to be approximately $180 \mathrm{~nm}$. Hydroxyl groups present on the silica NP surface were converted to thiols, and the Ag NPs were introduced directly onto the modified surface via the reduction of $\mathrm{AgNO}_{3}$ in solution. Figure S4 shows the transmission electron microscopy (TEM) image of the prepared $\mathrm{SiO}_{2} @ \mathrm{Ag}$ NPs. As amine groups exhibit affinity for metals and form amine-metal complexes, Et- $\beta-\mathrm{CD}$ can be immobilized on the $\mathrm{SiO}_{2} @ \mathrm{Ag}$ NPs by simple mixing with stirring. To examine the optical properties of $\mathrm{SiO}_{2} @ \mathrm{Ag}$, UV-visible (UV-Vis) spectra were recorded (Figure S2). The UV-Vis spectra of both unmodified and modified $\mathrm{SiO}_{2} @ \mathrm{Ag}$ with Et- $\beta-\mathrm{CD}$ displayed a broad band from 325 to $650 \mathrm{~nm}$. 
In particular, in both cases, a maximum peak at around $430 \mathrm{~nm}$ was observed, corresponding to $\mathrm{Ag}$ $\mathrm{NPs}$ on the silica NP surface. After the functionalization of $\mathrm{Et}-\beta-\mathrm{CD}$ on $\mathrm{SiO}_{2} @ \mathrm{Ag}$, the maximum peak decreased in intensity and shifted slightly from 425 to $435 \mathrm{~nm}$.

\subsection{Detection of Flavonoids via SERS Using $S_{2} O_{2} @ A g @ E t-\beta-C D N P s$}

To verify whether $\mathrm{SiO}_{2} @ \mathrm{Ag} @ \mathrm{Et}-\beta-\mathrm{CD}$ NPs can detect flavonoids effectively and to evaluate the detection ability and stability of $\mathrm{SiO}_{2} @ \mathrm{Ag} @ \mathrm{Et}-\beta-\mathrm{CD}$ NPs as a sensor, systematic studies were performed with various flavonoids.

\subsubsection{Detection of Various Flavonoids Using Et- $\beta$-CD-Immobilized Ag-NP-Assembled Silica NPs}

For flavonoid detection, a $\mathrm{SiO}_{2} @ \mathrm{Ag} @ \mathrm{Et}-\beta-\mathrm{CD} N \mathrm{NP}$ solution was mixed with the target molecules for $1 \mathrm{~h}$ and transferred to capillary tubes, and then Raman spectra were measured. To investigate the flavonoid detection capability of the $\mathrm{SiO}_{2} @ \mathrm{Ag} @ \mathrm{Et}-\beta-\mathrm{CD} \mathrm{NPs}$, they were mixed with Nar, Hes, Que, and Lut $\left(10^{-4} \mathrm{M}\right)$, and the SERS spectra were recorded (Figure $\left.3 \mathrm{a}\right)$. In the absence of flavonoids, as the control studies, the spectrum of the $\mathrm{SiO}_{2} @ \mathrm{Ag} \mathrm{NPs}$ in ethanol (EtOH) showed only the peaks of ethanol and polyvinylpyrrolidone (PVP). The prominent band at $883 \mathrm{~cm}^{-1}$ belonged to $\mathrm{EtOH}$, and other smaller bands at 1001, 1053, 1095, and $1600 \mathrm{~cm}^{-1}$ characteristic of PVP also appeared. When Et- $\beta-C D$ was attached to the $\mathrm{SiO}_{2} @ \mathrm{Ag}$ NPs as a linker without any flavonoids, the resulting $\mathrm{SiO}_{2} @ \mathrm{Ag} @ \mathrm{Et}-\beta-\mathrm{CD}$ NPs in EtOH exhibited a prominent EtOH band at $883 \mathrm{~cm}^{-1}$ with other smaller bands at 1050, 1095, and $1455 \mathrm{~cm}^{-1}$. However, the bands at 1001 and $1600 \mathrm{~cm}^{-1}$ were absent, which indicated that PVP could be removed from the nanoparticle surface via replacement with a reactive molecule. However, in the presence of flavonoids, the SERS spectra of the $\mathrm{SiO}_{2} @ \mathrm{Ag} @ \mathrm{Et}-\beta-\mathrm{CD}$ NPs showed different characteristic SERS bands depending on the binding flavonoid. For example, the spectrum of Nar showed SERS bands at 548 and $1158 \mathrm{~cm}^{-1}$; that of Hes showed SERS bands at 457, 620, 1278 , and $1342 \mathrm{~cm}^{-1}$; and that of Que showed SERS bands at 520,715, and $848 \mathrm{~cm}^{-1}$. The spectrum of Lut with the $\mathrm{SiO}_{2} @ \mathrm{Ag} @ \mathrm{Et}-\beta-\mathrm{CD}$ NPs showed significantly stronger SERS bands at 422, 496, 513, $561,684,742$, and $1123 \mathrm{~cm}^{-1}$. These results show that $\mathrm{SiO}_{2} @ A g @ E t-\beta-C D$ NPs exhibit high affinity for Lut; this selectivity was caused by the structural differences of the four flavonoids (Figure 1). The characteristics of the guest molecules, such as structure-dependent properties like hydrophobicity and polarizability, may affect the selectivity of the complex. The spectrum of Lut showed the highest SERS intensity after binding with CD because of the differences in the electrostatic interactions of each complex, particularly hydrogen bonding $[20,48]$. To investigate the effect of a linker, we measured the SERS signals of model flavonoid Lut in the presence of $\mathrm{SiO}_{2} @ \mathrm{Ag}$ NPs with and without Et- $\beta-\mathrm{CD}$ (Figure 3b). Lut in EtOH did not show its characteristic peaks except for the EtOH peaks, even though a high concentration was introduced (Figure $3 b(i i i)$ ), owing to its low scattering extinction. However, Lut with and without Et- $\beta-C D$ showed its characteristic peaks. In the absence of Et- $\beta-C D$ (Si@Ag), Lut showed characteristic peaks at 428, 514, 533, 605, 746, 955, 1116, 1208, 1237, 1296, 1481 , and $1546 \mathrm{~cm}^{-1}$ because of the electromagnetic enhancement caused by the $\mathrm{SiO}_{2} @ \mathrm{Ag} \mathrm{NPs}$ (Figure $3 \mathrm{~b}(\mathrm{vi})$ ). In contrast, in the presence of $\mathrm{SiO}_{2} @ \mathrm{Ag} @ \mathrm{Et}-\beta-\mathrm{CD}$ NPs, the characteristic peaks of Lut were observed at $422,496,513,531,561,602,684,742,946,1123,1199,1229,1245,1293,1359,1461,1496$, and $1560 \mathrm{~cm}^{-1}$ (Figure $3 \mathrm{~b}(\mathrm{v})$ ). Comparison of these two spectra showed that the peaks of Lut with $\mathrm{SiO}_{2} @ \mathrm{Ag} @ \mathrm{Et}-\beta-\mathrm{CD}$ NPs were slightly shifted. The appearance of the new peaks at $496,561,684$, $1245,1359,1461$, and $1496 \mathrm{~cm}^{-1}$ and the increases in peak intensity at 513, 602, 742, 946, 1199, 1229, and $1293 \mathrm{~cm}^{-1}$ confirmed that Lut interacted selectively with Et- $\beta-C D$, causing the functional group of Lut to move near the surface of the Ag NPs.

Subsequently, additional experiments were conducted to evaluate the selectivity of the $\mathrm{SiO}_{2} @ A g @ E t-\beta-C D$ NPs for Lut. $\mathrm{SiO}_{2} @ A g @ E t-\beta-C D$ NPs were mixed with different organic compounds (ethylene glycol, $\beta$-estradiol, isopropyl alcohol, naphthalene, toluene, or Lut) at a concentration of $10^{-4} \mathrm{M}$. Unlike the mixtures containing flavonoids and the $\mathrm{SiO}_{2} @ \mathrm{Ag} @ \mathrm{Et}-\beta-\mathrm{CD}$ NPs, the organic-compound-containing solutions did not show any characteristic peaks in their Raman spectra (Figure S5a). To further study the selectivity of the $\mathrm{SiO}_{2} @ \mathrm{Ag} @ \mathrm{Et}-\beta-\mathrm{CD}$ NPs, another control 
experiment involving aniline with $\mathrm{SiO}_{2} @ \mathrm{Ag} \mathrm{NPs}$ and $\mathrm{SiO}_{2} @ \mathrm{Ag} @ \mathrm{Et}-\beta-\mathrm{CD}$ NPs was conducted, and the results are displayed in Figure S4b. Aniline can bind to a metal through the non-paired electrons of its amino group. Its characteristic SERS peaks were observed at 1236, 1550, and $1581 \mathrm{~cm}^{-1}$ upon $^{-}$ binding with $\mathrm{SiO}_{2} @ \mathrm{Ag}$ NPs (Figure S5b(ii)). However, these characteristic peaks disappeared upon binding with $\mathrm{SiO}_{2} @ \mathrm{Ag} @ \mathrm{Et}-\beta-\mathrm{CD}$ NPs (Figure S5b(iii)). We believe that the Et- $\beta-\mathrm{CD}$ on the surface of the $\mathrm{SiO}_{2} @ \mathrm{Ag}$ NPs hinder the attachment of aniline to their surface. In the SERS spectrum of the mixed solution of aniline and Lut with $\mathrm{SiO}_{2} @ \mathrm{Ag} @ \mathrm{Et}-\beta-\mathrm{CD}$ NPs, only the characteristic peaks of Lut at $604,942,1203,1226$, and $1558 \mathrm{~cm}^{-1}$ are shown (Figure S5b(iv)). These results indicate that the $\mathrm{SiO}_{2} @ \mathrm{Ag} @ \mathrm{Et}-\beta-\mathrm{CD}$ NPs can be used for detecting flavonoids selectively. Therefore, $\mathrm{SiO}_{2} @ \mathrm{Ag} @ \mathrm{Et}-\beta-\mathrm{CD}$ exhibited selectivity towards Lut, owing to the recognition function of Et- $\beta-C D$, as can be seen by comparing Figure 3a line (vi) with the SERS spectra of complexes formed via non-specific interactions between the other flavonoids and pristine $\mathrm{SiO}_{2} @ \mathrm{Ag}$ shown in Figure S6.
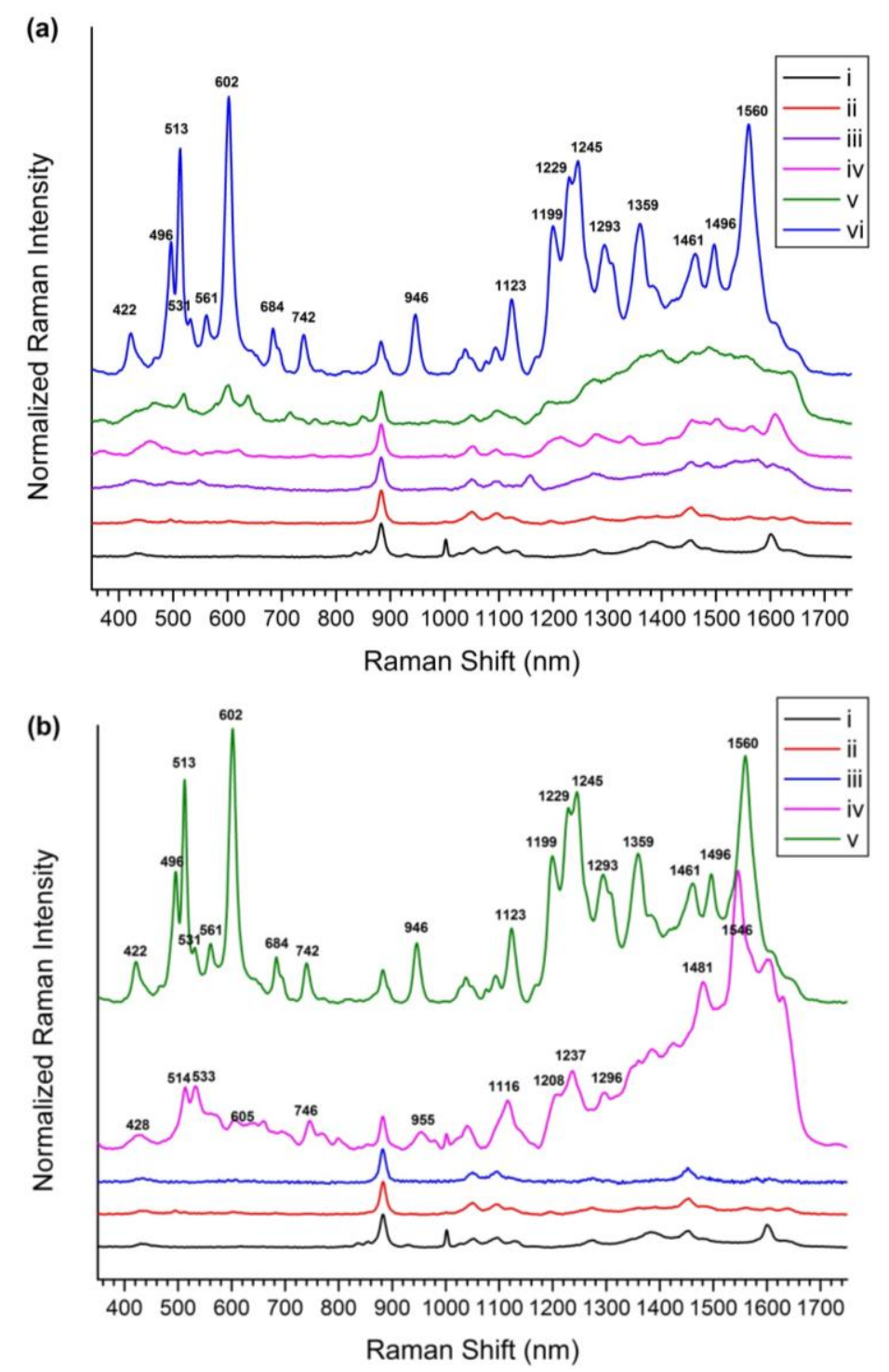

Figure 3. Surface enhanced Raman scattering (SERS) spectra. (a) SERS spectra of (i) silver nanoparticle (NP)-embedded silica NPs $\left(\mathrm{SiO}_{2} @ \mathrm{Ag} \mathrm{NPs}\right)$, (ii) $\mathrm{SiO}_{2} @ \mathrm{Ag} @ \mathrm{Et}-\beta-\mathrm{CD} \mathrm{NPs}$, (iii) $\mathrm{SiO}_{2} @ \mathrm{Ag} @ \mathrm{Et}-\beta-\mathrm{CD}$ NPs with Nar, (iv) $\mathrm{SiO}_{2} @ \mathrm{Ag} @ \mathrm{Et}-\beta-\mathrm{CD}$ NPs with Hes, (v) $\mathrm{SiO}_{2} @ \mathrm{Ag} @ \mathrm{Et}-\beta-\mathrm{CD}$ NPs with Que, and (vi) $\mathrm{SiO}_{2} @ \mathrm{Ag} @ \mathrm{Et}-\beta-\mathrm{CD}$ NPs with Lut; (b) SERS spectra of (i) $\mathrm{SiO}_{2} @ \mathrm{Ag} \mathrm{NPs}$, (ii) $\mathrm{SiO}_{2} @ \mathrm{Ag} @$ Et- $\beta$-CD NPs, (iii) Lut in ethanol $\left(10^{-2} \mathrm{M}\right)$, (iv) $\mathrm{SiO}_{2} @ \mathrm{Ag}$ NPs mixing with Lut $\left(10^{-4} \mathrm{M}\right)$, and (v) $\mathrm{SiO}_{2} @ \mathrm{Ag} @ \mathrm{Et}-\beta-\mathrm{CD}$ NPs mixing with Lut $\left(10^{-4} \mathrm{M}\right)$. 


\subsubsection{Determination of the Detection Limit of $\mathrm{SiO}_{2} @ \mathrm{Ag} @ \mathrm{Et}-\beta-\mathrm{CD}$ NPs for Lut}

To investigate the capability of the $\mathrm{SiO}_{2} @ \mathrm{Ag} @ \mathrm{Et}-\beta-\mathrm{CD}$ NPs for quantitative flavonoid detection, a $\mathrm{SiO}_{2} @ \mathrm{Ag} @ \mathrm{Et}-\beta-\mathrm{CD} \mathrm{NP}$ solution was treated with Lut solutions of various concentrations from $1 \times 10^{-3} \mathrm{M}$ to $1 \times 10^{-7} \mathrm{M}$ for $1 \mathrm{~h}$. Figure 4a shows the Raman spectra of the $\mathrm{SiO}_{2} @ \mathrm{Ag} @ \mathrm{Et}-\beta-\mathrm{CD}$ NPs mixed with Lut. The SERS intensity increased with the Lut concentration in the studied range, particularly the intensities of the peaks observed at $513,684,742$, and $1123 \mathrm{~cm}^{-1}$. Figure $4 \mathrm{~b}$ shows the normalized SERS intensity at $742 \mathrm{~cm}^{-1}$. The detection limit for Lut based on the SERS signals of the $\mathrm{SiO}_{2} @ \mathrm{Ag} @ \mathrm{Et}-\beta-\mathrm{CD}$ NPs was $10^{-7} \mathrm{M}$.

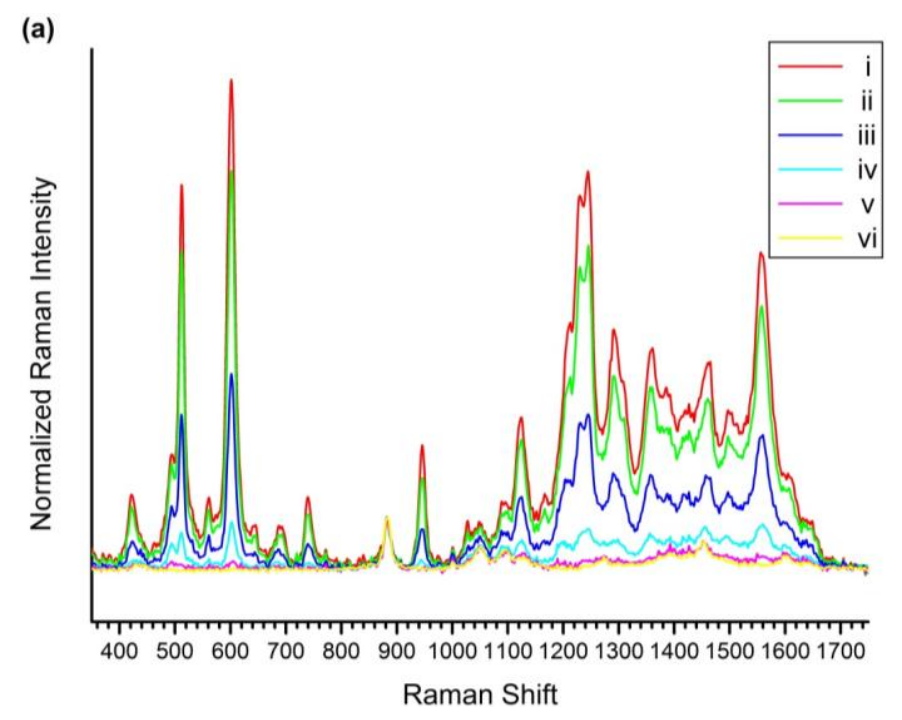

(b)

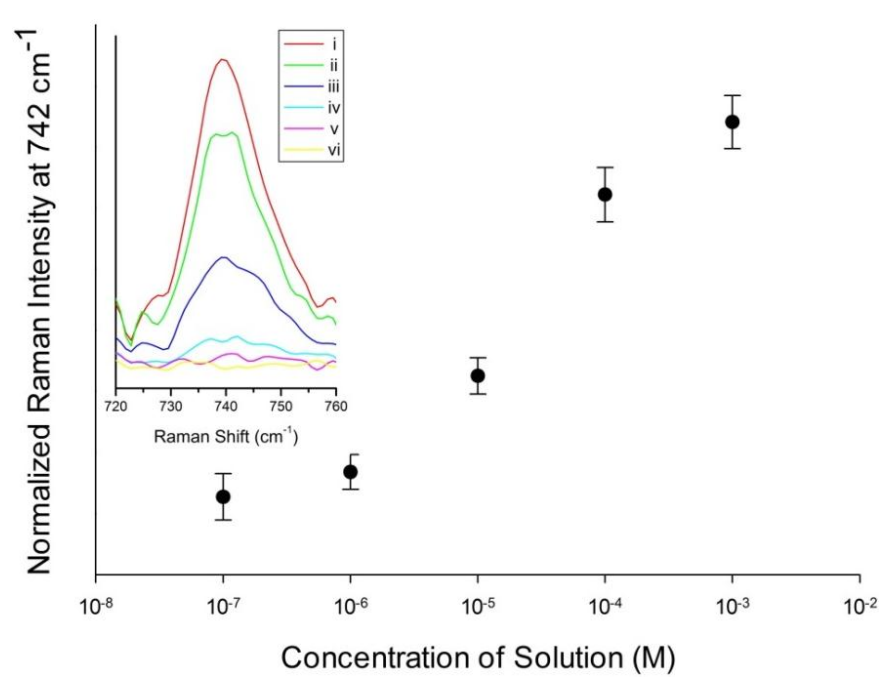

Figure 4. SERS spectra and normalized SERS intensity. (a) SERS spectra of $\mathrm{SiO}_{2} @ A g @ E t-\beta-C D$ NPs mixed with Lut at concentrations from $1 \times 10^{-3} \mathrm{M}$ to $1 \times 10^{-7} \mathrm{M}$; (b) Normalized SERS intensities at $742 \mathrm{~cm}^{-1}$ ((i) $10^{-3} \mathrm{M}$, (ii) $10^{-4} \mathrm{M}$, (iii) $10^{-5} \mathrm{M}$, (iv) $10^{-6} \mathrm{M}$, (v) $10^{-7} \mathrm{M}$, and (vi) $0 \mathrm{M}$ ).

\subsubsection{Stability of the Flavonoid Captured by Et- $\beta$-CD-Immobilized Ag-NP-Assembled Silica NPs}

To investigate the stability of Lut captured by $\mathrm{SiO}_{2} @ \mathrm{Ag} @ \mathrm{Et}-\beta-\mathrm{CD} N \mathrm{~N}$, the $\mathrm{SiO}_{2} @ \mathrm{Ag} @ \mathrm{Et}-\beta-\mathrm{CD}$ NPs were washed several times with ethanol to dissolve Lut, and the Raman intensity of the captured Lut at $742 \mathrm{~cm}^{-1}$ was measured after each washing. Figure 5a shows the Raman spectra of Lut captured by $\mathrm{SiO}_{2} @ \mathrm{Ag} @ \mathrm{Et}-\beta-\mathrm{CD}$ NPs after each wash with ethanol, and Figure 5b shows the normalized Raman 
intensities at $742 \mathrm{~cm}^{-1}$. No significant changes in the Raman intensity were observed after washing. Therefore, Lut captured by the $\mathrm{SiO}_{2} @ \mathrm{Ag} @ \mathrm{Et}-\beta-\mathrm{CD}$ NPs is stable even after washing five times.
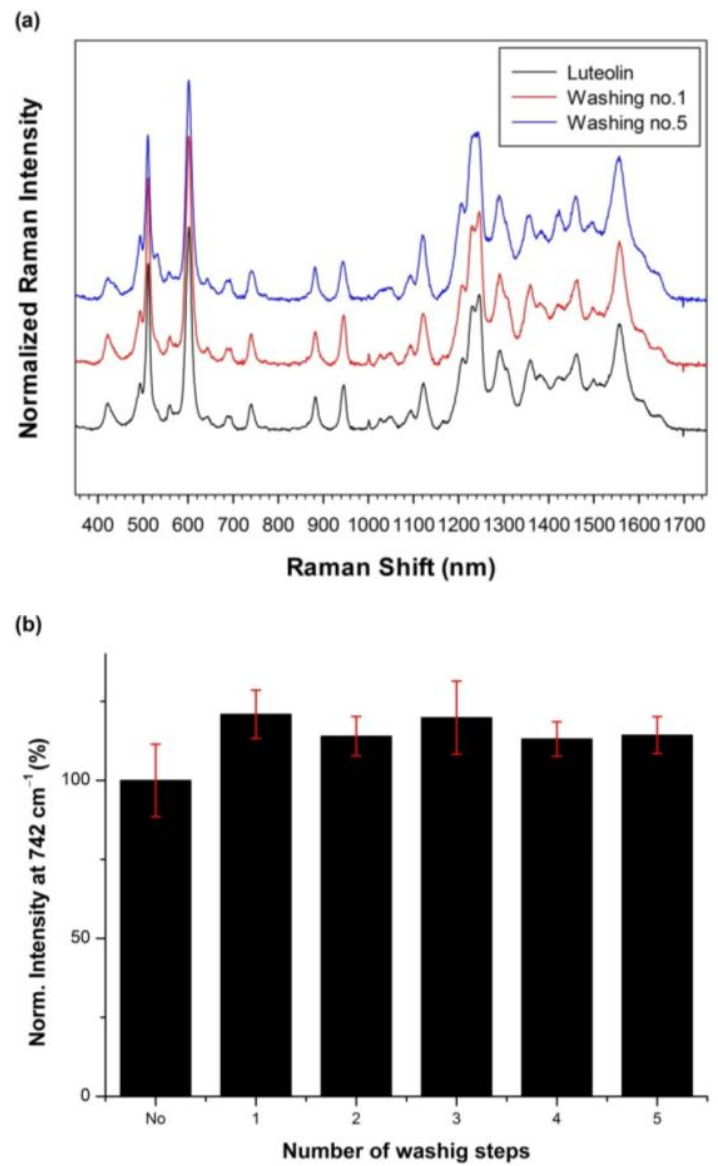

Figure 5. (a) Raman spectra and (b) normalized intensities of Lut captured by $\mathrm{SiO}_{2} @ \mathrm{Ag} @ \mathrm{Et}-\beta-\mathrm{CD} \mathrm{NPs}$ at $742 \mathrm{~cm}^{-1}$ after washing with ethanol (Lut concentration, $10^{-4} \mathrm{M}$ ).

\section{Materials and Methods}

\subsection{Chemicals}

$\beta-C D \quad\left(>95.0 \%\right.$, high-performance liquid chromatography, $\left.\mathrm{M}_{\mathrm{w}}=1134.99 \mathrm{Da}\right)$, 1-( $\boldsymbol{p}$-toluenesulfonyl)imidazole, Lut, Nar, and ethylenediamine were obtained from Tokyo Chemical Industry Co., Ltd. (Tokyo, Japan) HP- $\beta-C D\left(\mathrm{M}_{\mathrm{n}}=1460 \mathrm{Da}, 0.8\right.$ molar substitution), Hes, Que dehydrate, and DM- $\beta-C D$ were purchased from Sigma Aldrich (St. Louis, MO, USA). Deionized water was obtained from a Milli-Q system (Millipore, Saint-Quentin-en-Yvelines, France). Analytical-grade chemicals were used as received.

\subsection{Synthesis of Ethylenediamino- $\beta$-Cyclodextrin (Et- $\beta-C D)$}

First, tosylated $\beta-C D(3 \mathrm{~g}, 2.33 \mathrm{mmol})$ (Tos- $\beta-C D$, supplied by the Microbial Carbohydrate Resource Bank of Konkuk University, Seoul, Korea) was dissolved in ethylenediamine $(10 \mathrm{~mL})$ under $\mathrm{N}_{2}$ [49]. Then, the mixture was stirred at $75^{\circ} \mathrm{C}$ for $12 \mathrm{~h}$. After the reaction mixture had cooled to room temperature, a large volume of acetone (three volumes) was added for precipitation. The precipitated samples were dissolved in distilled water and separated using CM Sephadex C-25. After column separation, the samples were desalted using Bio-Gel P-2. The purity of the obtained solid ( $1 \mathrm{~g}, 0.85 \mathrm{mmol}$ ) was confirmed by matrix-assisted laser desorption/ionization time-of-flight (MALDI-TOF) mass spectrometry (Voyager-DE ${ }^{\mathrm{TM}}$ STR Bio-Spectrometry, Applied 
Biosystems, Framingham, MA, USA) and $600 \mathrm{MHz}$ NMR spectroscopy (Bruker Avance 600 spectrometer, Billerica, MA, USA) [50].

\subsection{UV Absorption Measurement of the Inclusion Complex}

First, an excess of each flavonoid $(500 \mu \mathrm{M})$ was added to $2 \mathrm{mM}$ of each of the aqueous solutions of $\beta-C D, H P-\beta-C D, D M-\beta-C D$, and Et- $\beta-C D$ in capped vials, and each of the solutions was subjected to sonication for $10 \mathrm{~min}$. Then, the solutions in the vials were stirred for $24 \mathrm{~h}$ at $25^{\circ} \mathrm{C}$ and kept in the dark to prevent degradation. After equilibrium was attained, the complexes were filtered using a $0.2 \mu \mathrm{m}$ polyvinylidene fluoride filter. Each sample was analyzed using a UV-Vis spectrophotometer (UV 2450, Shimadzu Corporation, Kyoto, Japan) from 220 to $400 \mathrm{~nm}$.

\subsection{Preparation of $\mathrm{SiO}_{2} @ A g @ E t-\beta-C D N P S$}

Ag-NP-assembled silica NPs $\left(\mathrm{SiO}_{2} @ \mathrm{Ag}\right)$ were synthesized according to previously reported methods [38]. The mass of the $\mathrm{SiO}_{2} @ A g$ NPs was determined as the dry weight at a specific volume. $\mathrm{SiO}_{2} @ \mathrm{Ag} \mathrm{NPs}(8 \mathrm{mg})$ were mixed with an $\mathrm{Et}-\beta-\mathrm{CD}$ solution $(4 \mathrm{mM}$ in water). The resulting suspension was stirred vigorously for $12 \mathrm{~h}$ at $25{ }^{\circ} \mathrm{C}$, centrifuged $(13,000 \mathrm{rpm}, 10 \mathrm{~min})$, washed with $\mathrm{EtOH}$, and re-dispersed in absolute $\mathrm{EtOH}(0.8 \mathrm{~mL})$. To determine the zeta potential of $\mathrm{SiO}_{2} @ \mathrm{Ag}$, its colloidal stability was determined using a zeta potential analyzer (ELS-8000, Otsuka Electronics, Osaka, Japan).

\subsection{Interactions of $\mathrm{SiO}_{2} @ A g @ E t-\beta-C D$ NPs with Flavonoids and Organic Molecules}

Each flavonoid and organic molecule stock solution $(100 \mathrm{mM})$ was prepared using absolute ethanol. The prepared $\mathrm{SiO}_{2} @ \mathrm{Ag} @ \mathrm{Et}-\beta-\mathrm{CD} N \mathrm{NP}(0.5 \mathrm{mg}$ in $50 \mu \mathrm{L}$ of EtOH$)$ were mixed with the stock solutions after diluting to the desired concentrations and then the mixtures were shaken for $1 \mathrm{~h}$ under ambient conditions.

\subsection{Raman Spectral Measurements}

To evaluate the sensitivity of the synthesized SERS materials, they were transferred to a capillary tube and measured using a DXR ${ }^{\mathrm{TM}}$ Raman Microscope system (Thermo Fisher Scientific, Waltham, MA, USA). The SERS spectra were recorded in backscattering geometry using a $10 \times$ objective lens. A $532 \mathrm{~nm}$ diode-pumped solid-state laser was used as the photoexcitation source, with a laser power of $5 \mathrm{~mW}$. Selected sites were randomly measured, and all SERS spectra were integrated for $2 \mathrm{~s}$. The spot size of the laser beam was $\sim 2 \mu \mathrm{m}$.

\section{Conclusions}

In this study, Et- $\beta$-CD-immobilized Ag-NP-embedded silica NPs ( $\left.\mathrm{SiO}_{2} @ \mathrm{Ag} @ \mathrm{Et}-\beta-\mathrm{CD} \mathrm{NPs}\right)$ were prepared for the detection of flavonoids (i.e., Hes, Nar, Que, and Lut). Based on its high affinity for flavonoids, Et $-\beta-C D$ could be used as a ligand for their SERS detection. As the strongest SERS bands were observed for Lut, the selectivity and sensitivity in the detection of Lut using $\mathrm{SiO}_{2} @ \mathrm{Ag} @ \mathrm{Et}-\beta-\mathrm{CD}$ NPs were also investigated. In this system, the limit of detection (LOD) for Lut was $10^{-7} \mathrm{M}$, and the Lut captured by $\mathrm{SiO}_{2} @ \mathrm{Ag} @ \mathrm{Et}-\beta-\mathrm{CD}$ NPs was stable even after washing five times. Based on this study, we propose the use of $\mathrm{SiO}_{2} @ \mathrm{Ag} @ \mathrm{Et}-\beta-\mathrm{CD}$ NPs for the SERS-based detection of flavonoids. In addition, this assembled structure hybridized with capturing ligands serves as a promising platform for the design of sensitive and selective sensing nanomaterials.

Supplementary Materials: The following are available online at http://www.mdpi.com/2079-4991/7/1/8/s1.

Acknowledgments: This work was supported by WTU Joint Research Grants of Konkuk University. This research was also supported by Basic Science Research Program through the National Research Foundation of Korea (NRF) funded by the Ministry of Education (NRF-2015R1D1A1A01058686) SDG.

Author Contributions: Jae Min Choi, Eunil Hahm, Bong-Hyun Jun, and Seunho Jung conceived and designed the experiments; Jae Min Choi, Eunil Hahm, Kyeonghui Park, Daham Jeong, Won-Yeop Rho, and Jaehi Kim performed the experiments; Jae Min Choi and Eunil Hahm analyzed the data; Dae Hong Jeong, Yoon-Sik Lee, 
Sung Ho Jhang, and Hyun Jong Chung contributed reagents/materials/analysis tools; Jae Min Choi, Eunil, Eunae Cho, Bong-Hyun Jun, and Seunho Jung wrote the paper; Jae-Hyuk Yu, Bong-Hyun Jun, and Seunho Jung supervised and provided consultation during the project.

Conflicts of Interest: The authors declare no conflict of interest.

\section{References}

1. Middleton, E. Effect of plant flavonoids on immune and inflammatory cell function. In Flavonoids in the Living System; Manthey, J.A., Buslig, B.S., Eds.; Springer: Boston, MA, USA, 1998; pp. 175-182.

2. Harborne, J.B.; Williams, C.A. Advances in flavonoid research since 1992. Phytochemistry 2000, 55, 481-504. [CrossRef]

3. Williams, R.J.; Spencer, J.P.E.; Rice-Evans, C. Flavonoids: Antioxidants or signalling molecules? Free Radic. Biol. Med. 2004, 36, 838-849. [CrossRef] [PubMed]

4. Ravishankar, D.; Rajora, A.K.; Greco, F.; Osborn, H.M.I. Flavonoids as prospective compounds for anti-cancer therapy. Int. J. Biochem. Cell Biol. 2013, 45, 2821-2831. [CrossRef] [PubMed]

5. Burda, S.; Oleszek, W. Antioxidant and antiradical activities of flavonoids. J. Agric. Food Chem. 2001, 49, 2774-2779. [CrossRef] [PubMed]

6. Chowdhury, A.R.; Sharma, S.; Mandal, S.; Goswami, A.; Mukhopadhyay, S.; Majumder, H.K. Luteolin, an emerging anti-cancer flavonoid, poisons eukaryotic DNA topoisomerase I. Biochem. J. 2002, 366, 653-661. [CrossRef] [PubMed]

7. Liu-Smith, F.; Meyskens, F.L. Molecular mechanisms of flavonoids in melanin synthesis and the potential for the prevention and treatment of melanoma. Mol. Nutr. Food Res. 2016, 60, 1264-1274. [CrossRef] [PubMed]

8. Park, M.-Y.; Kim, J.-M.; Kim, J.-S.; Choung, M.-G.; Sung, M.-K. Chemopreventive action of anthocyanin-rich black soybean fraction in $A P C^{\mathrm{Min} /+}$ intestinal polyposis model. J. Cancer Prev. 2015, 20, 193-201. [CrossRef] [PubMed]

9. Jia, Z.; Nallasamy, P.; Liu, D.; Shah, H.; Li, J.Z.; Chitrakar, R.; Si, H.; McCormick, J.; Zhu, H.; Zhen, W. Luteolin protects against vascular inflammation in mice and TNF-alpha-induced monocyte adhesion to endothelial cells via suppressing IKB $\alpha / \mathrm{NF}-\kappa \mathrm{B}$ signaling pathway. J. Nutr. Biochem. 2015, 26, 293-302. [CrossRef] [PubMed]

10. Su, Y.; Ma, L.; Wen, Y.; Wang, H.; Zhang, S. Studies of the in vitro antibacterial activities of several polyphenols against clinical isolates of methicillin-resistant Staphylococcus aureus. Molecules 2014, 19, 12630-12639. [CrossRef] [PubMed]

11. Lin, Y.; Shi, R.; Wang, X.; Shen, H.-M. Luteolin, a flavonoid with potential for cancer prevention and therapy. Curr. Cancer Drug Targets 2008, 8, 634-646. [CrossRef] [PubMed]

12. Watson, D.G.; Oliveira, E.J. Solid-phase extraction and gas chromatography-mass spectrometry determination of kaempferol and quercetin in human urine after consumption of ginkgo biloba tablets. J. Chromatogr. B 1999, 723, 203-210. [CrossRef]

13. Hasler, A.; Sticher, O.; Meier, B. High-performance liquid chromatographic determination of five widespread flavonoid aglycones. J. Chromatogr. A 1990, 508, 236-240. [CrossRef]

14. Chen, G.; Zhang, H.; Ye, J. Determination of rutin and quercetin in plants by capillary electrophoresis with electrochemical detection. Anal. Chim. Acta 2000, 423, 69-76. [CrossRef]

15. He, C.; Cui, H.; Zhao, X.; Zhao, H.; Zhao, G. Determination of rutin by flow injection with inhibited chemiluminescence detection. Anal. Lett. 1999, 32, 2751-2759. [CrossRef]

16. Nie, S.; Emory, S.R. Probing single molecules and single nanoparticles by surface-enhanced Raman scattering. Science 1997, 275, 1102-1106. [CrossRef] [PubMed]

17. Kneipp, K.; Wang, Y.; Kneipp, H.; Perelman, L.T.; Itzkan, I.; Dasari, R.R.; Feld, M.S. Single molecule detection using surface-enhanced Raman scattering (SERS). Phys. Rev. Lett. 1997, 78, 1667. [CrossRef]

18. Del Valle, E.M.M. Cyclodextrins and their uses: A review. Process Biochem. 2004, 39, 1033-1046. [CrossRef]

19. Rekharsky, M.V.; Inoue, Y. Complexation thermodynamics of cyclodextrins. Chem. Rev. 1998, 98, 1875-1918. [CrossRef] [PubMed]

20. Szejtli, J. Introduction and general overview of cyclodextrin chemistry. Chem. Rev. 1998, 98, 1743-1754. [CrossRef] [PubMed] 
21. Kim, H.; Choi, J.; Jung, S. Inclusion complexes of modified cyclodextrins with some flavonols. J. Incl. Phenom. Macrocycl. Chem. 2009, 64, 43-47. [CrossRef]

22. Kim, H.; Kim, H.W.; Jung, S. Aqueous solubility enhancement of some flavones by complexation with cyclodextrins. Bull. Korean Chem. Soc. 2008, 29, 590-594.

23. Kwon, Y.; Kim, H.; Park, S.; Jung, S. Enhancement of solubility and antioxidant activity of some flavonoids based on the inclusion complexation with sulfobutylether $\beta$-cyclodextrin. Bull. Korean Chem. Soc. 2010, 31, 3035-3037. [CrossRef]

24. Kamphorst, A.O.; Mendes de Sa, I.; Faria, A.M.C.; Sinisterra, R.D. Association complexes between ovalbumin and cyclodextrins have no effect on the immunological properties of ovalbumin. Eur. J. Pharm. Biopharm. 2004, 57, 199-205. [CrossRef] [PubMed]

25. Patel, R.; Patel, M. Solid-state characterization and in vitro dissolution behavior of lorazepam: Hydroxypropyl-beta-cyclodextrin inclusion complex. Drug. Discov. Ther. 2010, 4, 442-452. [PubMed]

26. Uekama, K.; Hirayama, F.; Irie, T. Cyclodextrin drug carrier systems. Chem. Rev. 1998, 98, 2045-2076. [CrossRef] [PubMed]

27. Wang, X.; Brusseau, M.L. Solubilization of some low-polarity organic compounds by hydroxypropyl- $\beta$-cyclodextrin Environ. Sci. Technol. 1993, 27, 2821-2825. [CrossRef]

28. Ko, S.O.; Schlautman, M.A.; Carraway, E.R. Partitioning of hydrophobic organic compounds to hydroxypropyl-beta-cyclodextrin: Experimental studies and model predictions for surfactant-enhanced remediation applications. Environ. Sci. Technol. 1999, 33, 2765-2770. [CrossRef]

29. Khan, A.R.; Forgo, P.; Stine, K.J.; D'Souza, V.T. Methods for selective modifications of cyclodextrins. Chem. Rev. 1998, 98, 1977-1996. [CrossRef] [PubMed]

30. Torreggiani, A.; Trinchero, A.; Tamba, M.; Taddei, P. Raman and pulse radiolysis studies of the antioxidant properties of quercetin: $\mathrm{Cu}(\mathrm{II})$ chelation and oxidizing radical scavenging. J. Raman Spectrosc. 2005, 36, 380-388. [CrossRef]

31. Cornard, J.P.; Merlin, J.C. Spectroscopic and structural study of complexes of quercetin with $\mathrm{Al}(\mathrm{III})$. J. Inorg. Biochem. 2002, 92, 19-27. [CrossRef]

32. Cañamares, M.V.; Lombardi, J.R.; Leona, M. Raman and surface enhanced Raman spectra of 7-hydroxy flavone and $3^{\prime}, 4^{\prime}$ dihydroxy flavone. E-Preserv. Sci. 2009, 6, 81-88.

33. Jurasekova, Z.; Garcia-Ramos, J.V.; Domingo, C.; Sanchez-Cortes, S. Surface-enhanced Raman scattering of flavonoids. J. Raman Spectrosc. 2006, 37, 1239-1241. [CrossRef]

34. Teslova, T.; Corredor, C.; Livingstone, R.; Spataru, T.; Birke, R.L.; Lombardi, J.R.; Cañamares, M.V.; Leona, M. Raman and surface-enhanced Raman spectra of flavone and several hydroxy derivatives. J. Raman Spectrosc. 2007, 38, 802-818. [CrossRef]

35. Cornard, J.P.; Boudet, A.C.; Merlin, J.C. Complexes of Al(III) with $3^{\prime} 4^{\prime}$-dihydroxy-flavone: Characterization, theoretical and spectroscopic study. Spectrochim. Acta A 2001, 57, 591-602. [CrossRef]

36. Jurasekova, Z.; Torreggiani, A.; Tamba, M.; Sanchez-Cortes, S.; Garcia-Ramos, J.V. Raman and surface-enhanced Raman scattering (SERS) investigation of the quercetin interaction with metals: Evidence of structural changing processes in aqueous solution and on metal nanoparticles. J. Mol. Struct. 2009, 918, 129-137. [CrossRef]

37. Yuan, W.; He, J.M.; Hui, C.; Zhang, D.S.; Hua, C.; Shao, H.B. Analysis of flavones in rubus parvifolius linn by high performance liquid chromatography-electrospray ionization mass spectroscopy and thin layer chromatography-fourier transform surface enhanced Raman spectroscopy. Chin. J. Anal. Chem. 2006, 34, 1073-1077. [CrossRef]

38. Hahm, E.; Jeong, D.; Cha, M.G.; Choi, J.M.; Pham, X.-H.; Kim, H.-M.; Kim, H.; Lee, Y.-S.; Jeong, D.H.; Jung, S. $\beta$-CD dimer-immobilized Ag assembly embedded silica nanoparticles for sensitive detection of polycyclic aromatic hydrocarbons. Sci. Rep. 2016, 6, 26082. [CrossRef]

39. Ramasamy, M.; Yi, D.K.; An, S.S.A. Enhanced detection sensitivity of Escherichia coli O157: H7 using surface-modified gold nanorods. Int. J. Nanomed. 2015, 10, 179-190.

40. Kim, J.-H.; Kim, J.-S.; Choi, H.; Lee, S.-M.; Jun, B.-H.; Yu, K.-N.; Kuk, E.; Kim, Y.-K.; Jeong, D.H.; Cho, M.-H. Nanoparticle probes with surface enhanced Raman spectroscopic tags for cellular cancer targeting. Anal. Chem. 2006, 78, 6967-6973. [CrossRef] [PubMed]

41. Singh, R.; Bharti, N.; Madan, J.; Hiremath, S. Characterization of cyclodextrin inclusion complexes-A review. J. Pharm. Sci. Technol. 2010, 2, 171-183. 
42. Uekama, K.; Fujinaga, T.; Hirayama, F.; Otagiri, M.; Yamasaki, M. Inclusion complexations of steroid hormones with cyclodextrins in water and in solid phase. Int. J. Pharm. 1982, 10, 1-15.

43. Rajagopalan, N.; Chen, S.C.; Chow, W.-S. A study of the inclusion complex of amphotericin-B with $\gamma$-cyclodextrin. Int. J. Pharm. 1986, 29, 161-168. [CrossRef]

44. Al-Marzouqi, A.H.; Shehatta, I.; Jobe, B.; Dowaidar, A. Phase solubility and inclusion complex of itraconazole with $\beta$-cyclodextrin using supercritical carbon dioxide. J. Pharm. Sci. 2006, 95, 292-304. [CrossRef] [PubMed]

45. Jadhav, G.S.; Vavia, P.R. Physicochemical, in silico and in vivo evaluation of a danazol- $\beta$-cyclodextrin complex. Int. J. Pharm. 2008, 352, 5-16. [CrossRef] [PubMed]

46. Chow, D.D.; Karara, A.H. Characterization, dissolution and bioavailability in rats of ibuprofen- $\beta$-cyclodextrin complex system. Int. J. Pharm. 1986, 28, 95-101. [CrossRef]

47. Stöber, W.; Fink, A.; Bohn, E. Controlled growth of monodisperse silica spheres in the micron size range. J. Colloid Interface Sci. 1968, 26, 62-69. [CrossRef]

48. Szejtli, J. Selectivity/structure correlation in cyclodextrin chemistry. Supramol. Chem. 1995, 6, $217-223$. [CrossRef]

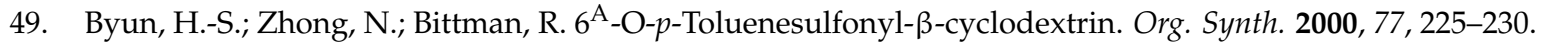

50. Bonomo, R.P.; Cucinotta, V.; Allessandro, F.D.; Impellizzeri, G.; Maccarrone, G.; Rizzarelli, E.; Vecchio, G. Coordination properties of 6-deoxy-6-[1-(2-amino) ethylamino]- $\beta$-cyclodextrin and the ability of its copper(II) complex to recognize and separate amino acid enantiomeric pairs. J. Incl. Phenom. Macrocycl. Chem. 1993, 15, 167-180. [CrossRef]

(C) 2017 by the authors; licensee MDPI, Basel, Switzerland. This article is an open access article distributed under the terms and conditions of the Creative Commons Attribution (CC-BY) license (http://creativecommons.org/licenses/by/4.0/). 